Table 1. The prevalence of the Factor V Leiden mutation in Japanese diabetic and non-diabetic subjects

\begin{tabular}{llllll}
\hline & $n$ & Males/Females & Age (years) & Age range (years) & Leiden mutation \\
\hline NIDDM patients & 314 & $184 / 130$ & $57.7 \pm 11.4$ & $31-87$ & 0 \\
Non-diabetic subjects & 139 & $78 / 61$ & $49.5 \pm 14.0$ & $40-82$ & 0 \\
\hline
\end{tabular}

Data are mean \pm SD

Arg506Gln mutation in the gene for factor V (Factor V Leiden). N Engl J Med 336: 399-403

3. Krekora K, De Lucia D, Capani F, Donati MB, Iacoviello L (1996) Association of coagulation factor V (Arg506Gln) mutation with non-insulin-dependent diabetes mellitus. Lancet 348: 1666-1667

4. Ceriello A, Taboga C, Tonutti L et al (1996) Post-meal coagulation activation in diabetes mellitus: the effect of acarbose. Diabetologia 39: 469-473

5. Chan P, Pan WH (1996) Coagulation activation in type 2 diabetes mellitus: the higher coronary risk of female diabetic patients. Diab Med 12: 504-507

6. Sowers JR, Epstein M (1995) Diabetes mellitus and associated hypertension, vascular disease, and nephropathy. An update. Hypertension 26: 869-879

7. Stegmayr B, Asplund K (1995) Diabetes as a risk factor for stroke. A population perspective. Diabetologia 38: 10611068
8. Gruden G, Olivetti C, Cavallo-Perin P et al (1997) Activated protein $\mathrm{C}$ resistance in type 1 diabetes. Diabetes Care 20: 424-425

9. World Health Organization (1985) Diabetes mellitus report of a WHO Study Group Second Report. Geneva, World Health Organization Technical Reports Series no. 727

10. Hager J, Hansen L, Vaisse C et al (1995) A missense mutation in the glucagon receptor gene is associated with non-insulin-dependent diabetes mellitus. Nat Genet 9: 299-304

11. Odawara M, Tachi Y, Yamashita K (1996) Absence of association between the Gly40-Ser mutation in the human glucagon receptor and Japanese patients with non-insulin-dependent diabetes mellitus or impaired glucose tolerance. Hum Genet 98: 636-639

12. Rees DC, Cox M, Clegg JB (1995) World distribution of factor V Leiden. Lancet 346: 1133-1134

\section{Anti-ganglioside GM1 antibody and distal symmetric "diabetic polyneuropathy" with dominant motor features}

\begin{abstract}
Dear Sir,
The prevailing hypothesis of the pathogenesis of chronic diabetic complications is that hyperglycaemia initiates complex metabolic perturbations, which result in pathologic changes in various organs, including the peripheral nervous system. This was amply supported by the Diabetes Control and Complications Trial (DCCT) wherein near normoglycaemia reduced the risk for development of complications [1]. However, once neuropathy is established it proceeds inexorably and cannot be reversed by near-normal glycaemia, for example that achieved by pancreatic transplantation [2, 3]. This could be explained by the fact that neuropathy is a heterogeneous disorder with a multiplicity of aetiologies acting through vascular, immunologic, and metabolic factors [4, 5], as well as deficient neurotropic support that may also be involved in the progression of neurologic deficit in diabetic patients [4-6].

Activation of immune effectors may be another mechanism capable of causing neuropathy or perpetuating it, once established, by a variety of mechanisms. Immunopathologic studies have revealed the presence of antibodies $(\mathrm{Ab})$ and complement in the peripheral nerves of patients with distal symmetric polyneuropathy (DSPN), as well as increased numbers of cytotoxic T lymphocytes $[7,8]$. These findings support the concept of immune system involvement in the pathogenesis of diabetic neuropathy, in addition to the metabolic and microvascular abnormalities.
\end{abstract}

To further investigate immune phenomena in diabetic neuropathy, we screened a group of 67 consecutive patients with both diabetes and neuropathy for antibodies against various neuronal antigens, including sulfoglucuronyl paragloboside, sulfatide, neuronal nuclear antigen, myelin associated glycoprotein and the gangliosides: GM1; asialo

Table 1. Demographic characteristics, neuropathy scores (NSS, sensory NDS and motor NDS or MRCS) and quantitative sensory testing in $14 \mathrm{GM} 1 \mathrm{Ab}$ positive and $53 \mathrm{Ab}$ negative diabetic patients with DSPN

\begin{tabular}{lcc}
\hline & DSPN & $\begin{array}{c}\text { DSPN with anti- } \\
\text { GM1 antibodies }\end{array}$ \\
\hline$n$ & 53 & 14 \\
Age (years) & $54.6 \pm 2.1$ & $53 \pm 4.3$ \\
male/female & $32: 21$ & $6: 8$ \\
IDDM : NIDDM & $16: 37$ & $3: 11$ \\
Duration of diabetes (years) & $13.0 \pm 1.3$ & $15.2 \pm 2.6$ \\
Duration of neuropathy (months) & $40.2 \pm 7.7$ & $46.0 \pm 13.1$ \\
HbA ( $_{1 \mathrm{c}}(\%)$ & $8.1 \pm 0.5$ & $7.9 \pm 1.0$ \\
Height $(\mathrm{cm})$ & $171 \pm 1.5$ & $167 \pm 3.3$ \\
Weight $(\mathrm{kg})$ & $86.8 \pm 3.0$ & $75 \pm 4.9$ \\
Body mass index $\left(\mathrm{kg} / \mathrm{m}^{2}\right)$ & $29.4 \pm 1.0$ & $25.8 \pm 1.8$ \\
NSS & $3.2 \pm 0.3$ & $4.2 \pm 0.6$ \\
Sensory NDS & $23.4 \pm 2.3$ & $31.3 \pm 4.0$ \\
MRCS & $2.0 \pm 0.8$ & $6.5 \pm 1.5^{\mathrm{a}}$ \\
Vibration threshold $(\mathrm{VU})$ & $11.5 \pm 1.7$ & $11.9 \pm 2.9$ \\
Cold detection threshold $\left({ }^{\circ} \mathrm{C}\right)$ & $6.1 \pm 2.1$ & $9.0 \pm 3.3$ \\
Warm detection threshold $\left({ }^{\circ} \mathrm{C}\right)$ & $8.7 \pm 1.8$ & $10.9 \pm 1.5$ \\
Cold pain threshold $\left({ }^{\circ} \mathrm{C}\right)$ & $26.0 \pm 4.7$ & $28.0 \pm 1.9$ \\
Heat pain threshold $\left({ }^{\circ} \mathrm{C}\right)$ & $13.5 \pm 1.8$ & $14.4 \pm 3.4$ \\
\hline
\end{tabular}

Quantitative sensory testing included vibration threshold, cold and warm detection thresholds, and thermal pain thresholds Data are mean \pm SEM

VU, Vibration units; NSS, neuropathy symptom score; NDS, neuropathy disability score; MRCS, Medical Research Council Scale or motor neuropathy disability score ${ }^{\mathrm{a}} p<0.05$ 
GM1; and GD1b. We have previously shown that $88 \%$ of patients with diabetic neuropathy have phospholipid antibodies in their serum which correlated with sensory loss [9]. In this study we were particularly interested in neuropathy characterized by a predominance of motor features. The neurologic evaluation consisted of the assessment of neuropathy symptoms and disability score (all modified from that of Dyck and colleagues [10]), motor strength using the medical research council (MRC) scale for motor disability, quantitative sensory testing (QST) and electrophysiologic measurements [11].

Of the neuronal antibodies tested, only GM1 Ab was significantly elevated. Raised titres of anti-ganglioside GM1 antibody (GM1 Ab) (range from 14 to 152 EIA units, normal < 10 EIA units) were found in 14 patients $(20.8 \%)$. The duration of neuropathy, duration of diabetes and $\mathrm{HbA}_{1 c}$ results were similar in antibody $\mathrm{Ab}$ positive and $\mathrm{Ab}$ negative groups (Table 1). Motor disability score was significantly higher in the GM1 $\mathrm{Ab}$ positive patients as compared to $\mathrm{Ab}$ negative individuals $(6.5 \pm 1.5$ vs $2.0 \pm 0.8, p<0.01)$, indicating a more severe motor deficit in patients with a raised GM1 Ab titre. There was no direct correlation between antibody titre and nerve disability scores. The magnitude of the sensory deficit, measured by symptom score, sensory disability score and QST, was similar in the two groups. We also did not find a significant difference between the two groups in the electrophysiologic parameters tested (data not shown).

GM1 $\mathrm{Ab}$ were found in sera of patients with insulin-dependent diabetes (IDDM) and patients with non-insulin-dependent diabetes (NIDDM). This indicates that neuroimmunological abnormalities are not specific for the type of diabetes, but are associated with the polyneuropathy itself. It is not surprising that patients with NIDDM, as well as those with IDDM, present with neuroimmunological disturbances, since several other non-diabetic, immune-mediated peripheral neuropathies could occur in people with diabetes. For example, chronic inflammatory demyelinating polyneuropathy occurs more frequently in diabetes than the general population [12].

There are however, several possible explanations for our observations. It could be that these two phenomena, DSPN and raised GM1 Ab titre, occur in diabetic patients independently. Second, GM1 Ab may be an epiphenomenon associated with motor nerve damage, without a direct role in its pathogenesis. Lastly, it is possible that in some patients GM1 Ab are involved in motor nerve destruction and are an indicator of the pathogenic immune process. A number of observations already in the literature suggest that GM1 Ab have pathogenic potential in vitro and in vivo, mainly in the immune-mediated motor neuropathies $[13,14]$. These motor neuropathies respond favourably to various immunotherapeutic regimens. In their case report, Krendel et al. [12] suggested that predominantly motor diabetic neuropathy in diabetes may also respond to immunointervention. Our finding suggests that a proportion of patients with predominantly motor signs and symptoms may be GM1 Ab positive and therefore are candidates for immune therapies.

We also propose a prospective study of the markers of the immune system activation in patients with DSPN as a first step in the full scientific evaluation of these interesting observations.

Yours sincerely,

Z.Milicevic, P.G.Newlon, G.L.Pittenger, K.B.Stansberry, A. I. Vinik

\section{References}

1. Diabetes Control and Complications Trial Research Group (1993) The effect of intensive treatment of diabetes on the development and progression of long-term complications in insulin-dependent diabetes mellitus. N Engl J Med 329: 977-986

2. Kennedy WR, Navarro X, Goetz FC, Sutherland DER, Najarian JS (1990) Effects of pancreatic transplantation on diabetic neuropathy. N Engl J Med 322: 1031-1037

3. Vinik AI, Milicevic Z, Pittenger GL (1995) Beyond glycemia. Diabetes Care 18: 1037-1041

4. Vinik AI, Holland MI, LeBeau JM, Liuzzi FJ, Stansberry KB, Colen LB (1992) Diabetic neuropathies. Diabetes Care 15: 1926-1975

5. Vinik AI, Newlon PG, Lauterio TJet al. (1995) Nerve survival and regeneration in diabetes. Diabetes Rev 3 (1): 139-157

6. Apfel S, Adornato BT, Dyck PJ et al. (1996) Results of a double-blind, placebo-controlled trial of recombinant human nerve growth factor ( $\mathrm{rhNGF}$ ) in diabetic polyneuropathy. Annals of Neurology 40 (6): 954

7. Milicevic Z, Pittenger GL, Liuzzi FJ, Vinik AI (1995) Evidence for the presence of immunoglobulin-G (IgG) and $-\mathrm{M}$ (IgM) in sural nerve biopsies of patients with diabetic sensorimotor neuropathy. Diabetes 44: 63

8. Younger DS, Rosoklija G, Latov N, Hays AP (1995) Diabetic peripheral neuropathy: a clinicopathologic and immunohistochemical analysis of sural nerve biopsies. Muscle Nerve 19: 722-727

9. Vinik AI, Leichter SB, Pittenger GL et al. (1995) Phospholipid and glutamic acid decarboxylase autoantibodies in diabetic neuropathy. Diabetes Care 18 (9): 1225-1232

10. Dyck P, Kratz K, Lehman K (1991) The Rochester Diabetic Neuropathy Study: Design, criteria for types of neuropathy, selection bias, and reproducibility of neuropathic tests. Neurology 41: 799-807

11. Vinik AI, Suwanwalaikorn S, Stansberry KB, Holland MT, McNitt PM, Colen LE (1995) Quantitative measurement of cutaneous perception in diabetic neuropathy. Muscle Nerve 18 (6): 574-584

12. Krendel DA, Costigan DA, Hopkins LC (1995) Successful treatment of neuropathies in patients with diabetes mellitus. Arch Neurol 52: 1053-1061

13. Onsawa T, Miyatake T, Yuke N (1993) Anit-B-series ganglioside-recognizing autoantibodies in an acute sensory neuropathy cause cell death of rat dorsal root ganglion neurons. Neurosci Lett 157: 167-170

14. Ogino M, Orazio N, Latov N (1995) IgG anti-GM1 antibodies from patients with acute motor neuropathy are predominantly of the IgG1 and IgG3 subclasses. J Neuroimmunol 58: $77-80$ 